\title{
Interactive comment on "Subaqueous speleothems (Hells Bells) formed by the interplay of pelagic redoxcline biogeochemistry and specific hydraulic conditions in the El Zapote sinkhole, Yucatán Peninsula, Mexico" by Simon Michael Ritter et al.
}

\section{Anonymous Referee \#1}

Received and published: 18 February 2019

Having read the earlier work of this group on the Hells Bells features, I was delighted to read this manuscript. I general, I think the authors have put together an interesting study on some very curious features (the Hells Bells) and I look forward to seeing this study published in due course with minor revisions. I have only two major comments, with the rest being covered in the line-by-line comments, which l've copied below. First, I think the authors could expand the introduction beyond speleothems to draw in a wider readership. Hells Bells have been widely speculated about informally

Printer-friendly version

Discussion paper 
by karst researchers for several years, but I think that there is broader biogeochemical story that would be of interest to critical zone and coastal aquifer scientists. The authors don't have to take my suggestion in order for me to recommend publication, but I do think it would help broaden the appeal of the work. The second comment is a bit more substantive. I was not convinced that Hurricane activity would be likely to be responsible for sustained upward migration of the mixing zone necessary for Hells Bells to precipitate in areas above the modern redoxcline. The authors might explore droughts, which are well-documented in the Holocene (see Hodell et al., 2001, reference included in comments below), as an alternative process. Droughts would thin the freshwater lens and elevate the mixing zone for prolonged periods of time needed for the slow precipitation of calcite mentioned in the paper to form large Hells Bells features.

Abstract: Line 20: Given that this is a sinkhole, l'm uncomfortable with the author's description of this chamber as lightless in the absence of measurements of light intensity over annual timescales. While it may appear dark to divers, there may be some "light" that still makes it to the chamber during some portions of the year. Line 32: It would be nice if the authors could include information about why Hell's Bells are not more widely distributed in coastal aquifers in general (and the Yucatan more specifically) in the abstract. Improved information and word economy in the preceding sections should create space for this insertion. Page 2 Line 1: l've been working on karst research problems for almost 20 years and have never heard the term "pending speleothems." That doesn't mean the term does not exist, but it probably means it is not common. Page 3 lines 18-19: I don't understand why a recharge event would elevate the freshwater lens. It should depress it, as recharge would increase the thickness of the lens.... The manuscript that was cited wasn't much help in explaining the process either. Page 10, Line 3: I suggest "oxygenated" or "aerobic" as an alternative to "oxygenized" Page 11, Figure 3: The symbols change in panel $C$ but there is no corresponding legend. I'm guessing that the circles are still winch collected and the squares are diver collected, but it would be helpful if the symbols remained constant across each panel. Page 17

Printer-friendly version

Discussion paper
Interactive comment 
line 9: In this context, "though" is being used to contrast ideas and should not begin a sentence. I suggest restructuring this sentence and the previous one. Page 18 line 9: Bells should be plural. Page 18 lines 13-15: I can agree that sulfide oxidation drives calcite precipitation but I'm still clear on why these features are only found here and not in any of the other sulfidic halocline caves in the Yucatan (or elsewhere), but hopefully this is discussed later in the text..... Page 19 lines 23-24: I find these sentences super confusing. Can you please rephrase them? Page 19 line 28: change to "debris mound" Page 20 lines 6-8: I think the authors might want to make this section more clear by saying that methanogenesis in the presence of sulfate isn't expected, but that the methanogenesis could be occurring in the sediments where sulfate is reasonably expected to be depleted. I would then recommend they cite a manuscript or two from the marine sediment pore water research community to demonstrate this depletion is common. The authors' interpretation is also supported by the concentration profile, a point which should be emphasized in the discussion. Page 20, line 13: It might be more clear to say that $\mathrm{Fe}$ is only present in low concentrations in limestone and there are limited/no sources of siliciclastic materials that could contribute iron in this part of the Yucatan. Fe-oxides are common in many karst areas where the Fe is derived from weathering of siliciclastics. Page 24, Section 4.3.1 (entire section) - I find the role of Hurricanes in elevating the halocline to be a highly implausible explanation for the vertical zonation of the Hells Bells features. Hurricanes are infrequent and the "piston induced oscillation" effect described by the authors would be short lived. I find it hard to believe that any potential upward displacement by this mechanism would be of sufficient duration to allow for the precipitation of large masses of carbonate photographed above the modern redoxcline. I suggest that a more plausible scenario is that periods of drought (which are well-documented over the Holocence) lowered the water table and increased the elevation of the redoxcline for sustained periods of time (see Hodell, D.A., Brenner, M., Curtis, J.H. and Guilderson, T., 2001. Solar forcing of drought frequency in the Maya lowlands. Science, 292(5520), pp.1367-1370.) Page 27, line 19-20: I still wonder if the general orientation of all of the speleothems towards

Printer-friendly version

Discussion paper 
the center of the cenote indicates some phototaxic behavior. It would certainly be the simplest explanation and I would encourage the authors to measure light intensity over an annual cycle to see if perhaps small amounts of light are penetrating (not having visited this particular site, I'm unsure how likely this is, but the Cenote profile included in Fig 3, coupled with the fact that the cenote is sufficiently large in diameter to permit cavern tours, suggests that the entrance may be sufficiently large to allow some small amounts of light during some parts of the day/year). Page 28: Section 4.4 prerequisites for formation of Hells Bells. Many cenotes in the Yucatan meet these criteria yet lack Hells Bells. I wonder if one of the more unique aspects of El Zapote is the relatively thick mixing zone, which the authors highlight in their discussion. Many of the haloclines are much thinner, typically due to high flux of fresh or saline water (though I was surprised by how thin the halocline at Cenote Angelita was in the supporting literature - I wouldn't have guessed there was much flow in that location). I suppose many of the haloclines with high fluxes of organic material also have much greater light penetration (such as EI Pit and Cenote Angelita), so the location of the mixing zone in a dark cenote (I still hesitate to say that this is completely dark) is also likely important.

Interactive comment on Biogeosciences Discuss., https://doi.org/10.5194/bg-2018-520, 2019. 